\title{
Concomitant transsternal repair of a congenital Morgagni hernia and ventricular septal defect in a patient with Down syndrome
}

\author{
Mustafa Yllmaz (D), M. Melih Başaran (D), Ulaş Kumbasar (D), Baran Şimşek (D), İlhan Paşaoğlu
}

Department of Cardiovascular Surgery, Medical Faculty of Hacettepe University, Ankara, Turkey

Received: April 11, 2017 Accepted: May 05, 2017 Published online: April 24, 2019

\begin{abstract}
Congenital Morgagni hernias are uncommon diaphragmatic hernias. Some cases of congenital Morgagni hernias are associated with congenital malformations, including congenital heart defects, chest wall abnormalities, and some chromosomal anomalies. Congenital Morgagni hernias should be treated surgically via transthoracic or transabdominal approach. However, in patients undergoing open heart surgery for congenital heart defects, transsternal exposure and repair can be also used. Herein, we report a case of a ventricular septal defect and congenital Morgagni hernias associated with Down syndrome of which the defects were repaired concomitantly via sternotomy approach.
\end{abstract}

Keywords: Morgagni hernia; transsternal repair; ventricular septal defect.

Congenital Morgagni hernias $(\mathrm{CMH})$ are uncommon diaphragmatic hernias comprising about 3 to $5 \%$ of all types of congenital diaphragmatic hernias. ${ }^{[1,2]}$ Some cases of $\mathrm{CMH}$ are associated with congenital malformations, including congenital heart defects (i.e., atrial and/or ventricular septal defects, patent ductus arteriosus), chest wall abnormalities, and some chromosomal anomalies Down syndrome being the most common. ${ }^{[3-5]}$ Once diagnosed, surgical repair is indicated by either transabdominal or transthoracic approach. We, herein, report a case of a ventricular septal defect (VSD) and CMH associated with Down syndrome of which the defects were repaired concomitantly via sternotomy approach.

\section{CASE REPORT}

An 11-month-old male with Down syndrome was referred to our institution upon detection of cardiac murmur on physical examination. On chest $\mathrm{X}$-ray, gas-filled loops of the bowel were located within the right chest cavity. Lateral chest X-ray confirmed the diagnosis, showing a retrosternal radiolucent shadow. Echocardiography revealed a $4.5 \mathrm{~mm}$ subaortic ventricular septal defect with slight malalignment and a small secundum atrial septal defect. Chest computed tomography scan identified a $1.5 \times 2.7 \mathrm{~cm}$ diaphragmatic defect in the right cardiophrenic sinus and loops of bowel within the chest and confirmed the diagnosis of $\mathrm{CMH}$ (Figure 1).

We decided to close VSD and to repair the $\mathrm{CMH}$ concomitantly. Midline sternotomy was performed. Cardiopulmonary bypass (CPB) was instituted in a routine manner by aortic and bicaval cannulation. The VSD was closed using a Dacron ${ }^{\circledR}$ patch via right atrium. The patient weaned from CPB. Following completion of the cardiac procedure, right parietal pleura was opened. The diaphragmatic defect and the hernia sac which consist the transverse colon inside were visualized anteriorly close to the pericardiac fat. The hernia sac was dissected and lowered to the abdomen throughout the defect. The defect was repaired with a Dacron patch with interrupted sutures. Postoperative period was uneventful. The patient was discharged on postoperative Day 10.

Corresponding author: Baran Şimşek, MD. Hacettepe Üniversitesi Tip Fakültesi Kalp ve Damar Cerrahisi Anabilim Dal, 06100 Sihhiye, Ankara, Turkey.

Tel: +90 505 - 6972139 e-mail: simsekbaran@yahoo.com

\section{Citation:}

Yılmaz M, Başaran MM, Kumbasar U, Şimşek B, Paşaoğlu İ. Concomitant transsternal repair of a congenital Morgagni hernia and ventricular septal defect in a patient with Down syndrome. Cardiovasc Surg Int 2017;4(2):31-33. 


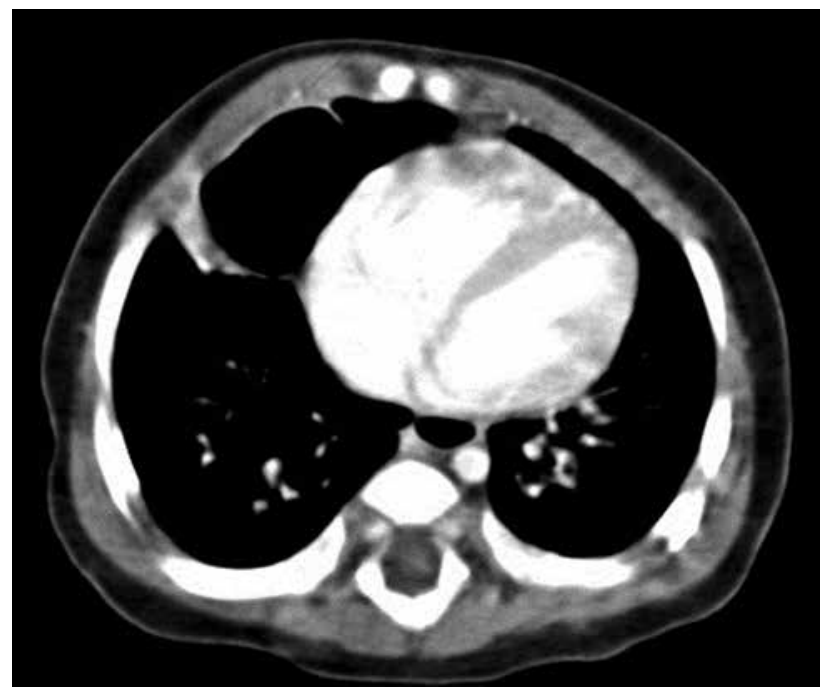

Figure 1. A $1.5 \times 2.7 \mathrm{~cm}$ diaphragmatic defect in the right cardiophrenic sinus and loops of bowel within the chest.

\section{DISCUSSION}

Anterior congenital diaphragmatic hernia through the foramen of Morgagni was first described by Giovani Morgagni in 1761..$^{[1,6]}$ The defect results from the failure of the fibrotendinous portion of the pars sternalis to fuse with the fibrotendinous part of the costochondral arches. ${ }^{[1,2,6]}$ Most (\%90) CMH occur on the right side, $2 \%$ on the left side, and $8 \%$ occur bilaterally. Pericardial attachment to the diaphragm, which is more common on the left side, supports and protects that side. The most common contents of the hernia sac are the colon, small bowels, liver, omentum, and stomach. ${ }^{[6]}$

It is well-known that CMH may be associated with other congenital anomalies such as congenital heart diseases, Down syndrome, intestinal malrotation, omphalocele, pectus carinatum, and genitourinary anomalies. ${ }^{[3]}$ However, chromosomal anomalies which are associated with $\mathrm{CMH}$ are more significant, in terms of whether it is an inheritable defect. ${ }^{[7,8]}$ In large series, it was reported that the incidence of $\mathrm{CMH}$ associated with Down syndrome was approximately $20 \%{ }^{[3]}$ It has also been reported that there is a possibility of muscular deficiency of the ventral paramedian segment of the body wall related to the diaphragm in Down syndrome. ${ }^{[9]}$

There is a common consensus which $\mathrm{CMH}$ should be treated surgically in symptomatic patients. Opinions differ as to the best surgical approach, whether transthoracic or transabdominal. ${ }^{[10,11]}$ However, in patients undergoing open heart surgery for congenital heart defects, as in our case, transsternal exposure and repair is also a possible option. ${ }^{[12]}$ Another controversial issue is the removal of the hernia sac during repair. Although some authors recommend excision of the hernia sac, others prefer to leave it as to avoid the possibility of pneumopericardium. ${ }^{[3,13]}$ However, there is no available data in the literature indicating whether leaving a hernia sac influences the rate of recurrence.

In conclusion, as congenital Morgagni hernias can be associated with congenital cardiac diseases, it should be kept in mind, in patients undergoing open heart surgery via sternotomy approach, that these defects can be repaired with transsternal approach as effective as other approaches without an additional incision.

\section{Declaration of conflicting interests}

The authors declared no conflicts of interest with respect to the authorship and/or publication of this article.

\section{Funding}

The authors received no financial support for the research and/or authorship of this article.

\section{REFERENCES}

1. Cullen ML, Klein MD, Philippart AI. Congenital diaphragmatic hernia. Surg Clin North Am 1985;65:1135-8.

2. Simson JNL, Eckstein HB. Congenital diaphragmatic hernia: a 20 years experience. Br J Surg 1985;72:733-6.

3. Salem AH, Nawaz A, Matta H, Jacobs A. Herniation through the foramen of Morgagni: early diagnosis and treatment. Pediatr Surg Int 2002;18:93-7.

4. Pokorny WJ, McGill CW, Harberg FH. Morgagni hernia during infancy: presentation and associated a nomalies. J Pediatr Surg 1984;19:394-7.

5. Vaos G, Skondras C. Colonic necrosis because of strangulated recurrent Morgagni's hernia in a child with Down's syndrome. J Pediatr Surg 2006;41:589-91.

6. Federico JA, Ponn RB. Foramen of Morgagni hernia. In: Shields TW, LoCicero III J, Ponn RB, editors. General Thoracic Surgery. 5th ed. Philadelphia: Lippincott Williams and Wilkins; 2000. p. 647-60.

7. Enns GM, Cox VA, Goldstein RB. Congenital diaphragmatic defects and associated syndromes, malformations, and chromosome anomalies: a retrospective study of 60 patients and literature review. Am J Med Genet 1998;79:215-25.

8. Slavotinec AM. The genetics of congenital diaphragmatic hernia. Semin Perinatol 2005;29:77-85.

9. Honore LH, Torfs CP, Curry CJ. Possible association between the hernia of Morgagni and trisomy 21. Am J Med Genet 1993;47:255-6. 
10. Kurkcuoglu IC, Eroglu A, Karaoglanoglu N, Polat P, Balik AA, Tekinbas C. Diagnosis and surgical treatment of Morgagni hernia: report of three cases. Surg Today 2003;33:525-8.

11. Kiliç D, Nadir A, Döner E, Kavukçu S, Akal M, Ozdemir N, et al. Transthoracic approach in surgical management of Morgagni hernia. Eur J Cardiothorac
Surg 2001;20:1016-9.

12. Mert M, Gunay I. Transsternal repair of Morgagni hernia ia a patient with coexistent ventricular septal defect and Down syndrome. Acta chir belg 2006;106:739-40.

13. Berman L1, Stringer D, Ein SH, Shandling B. The late presenting pediatric Morgagni hernia: a benign condition. J Pediatr Surg 1989;24:970-2. 